\title{
Editorial
}

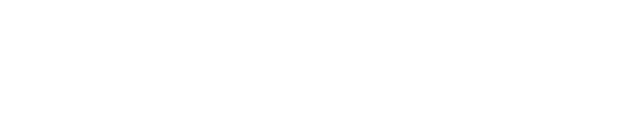

\section{Jerry Bagel}

Psoriasis Treatment Center of Central New Jersey, East Windsor, NJ, USA

Correspondence: Jerry Bagel Psoriasis Treatment Center of Central New Jersey, 59 One Mile Road, East Windsor, NJ 08520, USA

Tel + I 6094434500

$\mathrm{Fax}+\mathrm{I} 6094260530$

Email dreamacres I@aol.com
Twenty-five years ago, inpatient Goekerman therapy was considered to be the "gold standard" treatment for psoriasis. We thought PUVA (psoralen + ultraviolet A light) worked because it intercalated keratinocytes inhibiting cell division, methotrexate affected keratinocytic proliferation, and broadband ultraviolet B creating thymine dimers which also prevented keratinocytic proliferation. The idea that psoriasis was an immunologic disease was in its embryonic development.

With the utilization of five biologic agents approved by the US Food and Drug Administration, the pathogenesis is clearer, albeit far from completely understood. Clinicians also have much more knowledge regarding the safety and efficacy of these agents than we knew from the trial experience. The development of new drugs, biologic agents, small molecules, and those yet to be discovered requires a better understanding of the cause of psoriasis in terms of the "smoking gun", ie the molecular initiation of the cascade of events that results in psoriasis.

Although we have seen many advances over the past 25 years, I believe the pace of research is about to change. As we learn more about the comorbidities associated with psoriasis, we must learn new strategies to combat obesity, diabetes, metabolic syndrome, depression, and cardiovascular disease, and the effect these have in the workplace and at home. Furthermore, the evaluation of psoriasis is far from perfect, with the Psoriasis Area and Severity Index, Physician's Global Assessment, Dermatology Life Quality Index, and Koo-Mentor scale all having their limitations, both for the researcher and for the clinician.

"Psoriasis: Targets and Therapy" will hopefully allow all those interested in psoriasis to have expeditious access to new therapeutic advances in psoriasis. We have all seen how it can take at least six months to a year to have an article published, and that is at least three months after the data are complete.

Research and learning via the use of the online journal, paperless and green, will allow for peer-reviewed articles to be published quickly. As more effort is utilized to find better treatments and hopefully a cure for psoriasis, we will get the word out as quickly as possible about all new important data that can potentiate new thinking. The more we understand the mechanisms of action of drugs and the more we understand the pathogenesis of psoriasis, the closer we get to better treatments.

"Psoriasis: Targets and Therapy" opens up a new avenue for scientific inquiry, through the editorial page. I beg for your research studies, your voices will be heard. Your studies will hopefully help stimulate scientific discussion, resulting in submit your manuscript $\mid$ www.dovepress.com

Dovepress

http://dx.doi.org//0.2147/PTT.S21039
Psoriasis:Targets and Therapy 201 I:I I-2

(C) 20I I Bagel, publisher and licensee Dove Medical Press Ltd. This is an Open Access article which permits unrestricted noncommercial use, provided the original work is properly cited. 
better-designed studies, some even utilizing the evaluation of, eg Chinese and Indian treatments, and see if and why they work. Nutritional studies, the effect of yoga, massage, and other modalities also need to be explored.

I ask for your input and your research papers to keep an open-minded, evidence-based approach to make "Psoriasis:
Targets and Therapy" the most up-to-date and useful journal for those individuals involved in immunologic, genetic, epidemiologic, and clinical trial research, as well as for clinicians.

\section{Publish your work in this journal}

Psoriasis: Targets and Therapy is an international, peer-reviewed, open access journal focusing on psoriasis, nail psoriasis, psoriatic arthritis and related conditions, identification of therapeutic targets and the optimal

and quality of life. Visit http://www.dovepress.com/testimonials.php to read real quotes from published authors. 